\title{
3 Research Square

\section{Androgen Receptor Expression Associates With Distinctive Clinicopathological and Molecular Features in ER-Positive and ER-Negative Breast Cancer}

\section{Taobo Hu ( $\nabla$ thuac@connect.ust.hk)}

Peking University People's Hospital https://orcid.org/0000-0001-5124-7167

\section{Yiqiang Liu}

Peking University Cancer Hospital: Beijing Cancer Hospital

Guiyang Zhao

Beijing Changping Hospital

\section{Shu Wang}

Peking University People's Hospital

Mengping Long

Peking University Cancer Hospital: Beijing Cancer Hospital

\section{Research article}

Keywords: Androgen receptor, Estrogen receptor, Breast cancer, Molecular feature

Posted Date: October 12th, 2021

DOI: https://doi.org/10.21203/rs.3.rs-958949/v1

License: (c) (1) This work is licensed under a Creative Commons Attribution 4.0 International License.

Read Full License 


\section{Abstract \\ Background}

Androgen receptor (AR) expression is frequently observed in breast cancer, but its association with estrogen receptor (ER) expression of breast cancer remains unclear.

\section{Methods}

In this study, we analyzed the clinicopathological and molecular features associated AR loss in ERpositive and ER-negative breast cancer respectively, trying to elucidate the molecular correlation between $A R$ and $E R$.

\section{Results}

Our results showed that AR loss was associated with different clinicopathological characteristics in ERpositive and ER-negative breast cancer. Moreover, the expression of AR was correlated with different molecular features in ER-positive and ER-negative breast cancer.

\section{Conclusions}

These results suggest that the role of AR in ER-positive breast cancer is distinctive from that in ERnegative breast cancer.

\section{Background}

Breast cancer was the most common malignancy in women in which $70 \%-80 \%$ of them expressed steroid hormone receptor including estrogen receptor (ER) and progesterone receptor (PR) [1, 2]. ER-positive breast cancer was estrogen-dependent and was driven mostly by the activated ER pathway which was also effectively used as a therapeutic target. As another hormonal receptor, androgen receptor (AR) was expressed in $70-85 \%$ of all breast cancer and that ratio was about $10-63 \%$ in triple negative breast cancer (TNBC) which did not express ER, PR or HER2 [3, 4]. While in ER positive breast cancer, AR was expressed in $70 \%-95 \%$ of cases, varying in different studies $[4,5]$. The expression of AR was reported to be related with good prognosis in early breast cancer in terms of both disease-free survival and overall survival [6, 7]. While in ER+ and ER-breast cancer, the expression of AR was reported to have opposite prognostic value as AR expression was correlated with increased DFS in luminal breast cancer and decreased DFS in triple negative breast cancer (TNBC) [8].

While AR expression was more prevalent in breast cancer than $\operatorname{ER}[9,10]$, the detailed molecular role of AR in breast cancer still remains unresolved. AR has previous been shown to support estradiol mediated ER 
activity in ER+/AR+ breast cancer and AR inhibition can be synergized with tamoxifen to reduce proliferation of ER+ breast cancer [11]. A recent study showed that in ER-positive breast cancer, AR act as a tumor suppressor gene by inhibiting the binding of ER to the estrogen response elements (EREs) and consequently suppressing the activated ER pathway [12]. Moreover, the activity of AR pathway calculated by expression of a gene panel was positively correlated with disease-free survival in ER+ breast cancer, suggesting that AR agonist instead of antagonist should be applied in ER+ breast cancer. In ER- breast cancer, the expression of AR activates subsequent transcriptional program and its activation can promote cell proliferation $[13,14]$. Although prognostic value of AR expression was controversial, AR antagonist enzalutamide has been investigated for the treatment of TNBC patients with clinical benefit rate (CBR) reaching $33 \%$ at 16 weeks [15]. Selective androgen receptor modulators (SARMs) are clinically available and are being investigated as a medicine for AR-positive breast cancer $[16,17]$. It is important to understand the role of AR in ER+ and ER-breast cancer for the precise application of SARMs in breast cancer.

In this study, we analyzed the clinicopathological and molecular features associated AR loss in both ERpositive and ER-negative breast cancer and excluded HER2-amplified cases, trying to elucidate the molecular correlation between AR and ER. Our results shown that AR-positive breast cancer has better clinicopathological features that AR-negative BC especially in ER-negative subtype.

\section{Results}

\section{Correlation between expression of AR and clinicopathological features in ER+ and ER-breast cancer}

A total of 323 invasive breast cancer cases were recruited in our study diagnosed from September 2019 to May 2021 from Peking University Cancer Hospital (Figure 1). All cases have immunostaining or fluorescent in situ hybridization (FISH) result of ER, PR, AR and HER2. Positivity of ER, PR and AR was defined as $>=1 \%$ cancer cells showing positive nuclear staining. Two hundred and seventy-four cases (85\%) were ER positive and $49(15 \%)$ cases were ER negative. The clinicopathological characteristics between AR+ and AR- groups was analyzed and compared in ER+ and ER-breast cancer respectively (Table 1 and Table 2). 
Table 1

Clinicopathological characteristics of the ER+/AR- and ER+/AR+ group

\begin{tabular}{|llll|}
\hline Group & ER+/AR- (n=21) & ER+/AR+ (n=253) & $P$ \\
\hline Age & & & \\
\hline Mean (SD) & $52.2(11.7)$ & $53.5(11.4)$ & 0.603 \\
\hline Grade & & & 0.062 \\
\hline I & $1(4.8)$ & $26(10.3)$ & \\
\hline II & $16(76.2)$ & $212(83.8)$ & \\
\hline III & $4(19.0)$ & $15(5.9)$ & 0.835 \\
\hline Histology & & & \\
\hline IDC-NST & $21(100.0)$ & $243(96.0)$ & \\
\hline Invasive lobular carcinoma & $0(0)$ & $5(2.0)$ & \\
\hline Micropapillary carcinoma & $0(0)$ & $3(1.2)$ & \\
\hline Mucinous carcinoma & $0(0)$ & $2(0.8)$ & \\
\hline EGFR & & $1(0.4)$ & \\
\hline Negative & $16(76.2)$ & $210(83.0)$ & \\
\hline Positive & $3(14.3)$ & $16(6.3)$ & \\
\hline Unknown & $2(9.5)$ & $27(10.7)$ & \\
\hline CK5/6 & $19(90.5)$ & $246(97.2)$ & \\
\hline Negative & $2(9.5)$ & $6(2.4)$ & \\
\hline Positive & & & \\
\hline Unknown & & & \\
\hline PR & & & \\
\hline Negative & & & \\
\hline Positive & & & \\
\hline
\end{tabular}


Table 2

Clinicopathological characteristics of the ER-/AR- and ER-/AR+ group

\begin{tabular}{|c|c|c|c|}
\hline Group & ER-/AR- $(n=26)$ & $E R-/ A R+(n=23)$ & $P$ \\
\hline \multicolumn{4}{|l|}{ Age } \\
\hline Mean (SD) & $49.1(12.9)$ & $58.1(12.9)$ & 0.019 \\
\hline \multicolumn{4}{|l|}{ Grade } \\
\hline I & $0(0)$ & $0(0)$ & 0.016 \\
\hline II & $5(19.2)$ & $13(56.5)$ & \\
\hline III & $21(80.8)$ & $10(43.5)$ & \\
\hline \multicolumn{4}{|l|}{ Histology } \\
\hline IDC-NST & $26(100.0)$ & $22(95.7)$ & 0.951 \\
\hline Apocrine Carcinoma & & $1(4.3)$ & \\
\hline \multicolumn{4}{|l|}{ EGFR } \\
\hline Negative & $3(11.5)$ & $2(8.7)$ & 0.943 \\
\hline Positive & $21(80.8)$ & 19 (82.6) & \\
\hline Unknown & $2(7.7)$ & $2(8.7)$ & \\
\hline \multicolumn{4}{|l|}{ CK5/6 } \\
\hline Negative & $6(23.1)$ & $8(34.8)$ & 0.556 \\
\hline Positive & $20(76.9)$ & $15(65.2)$ & \\
\hline \multicolumn{4}{|l|}{ PR } \\
\hline Negative & $26(100.0)$ & $19(82.6)$ & 0.090 \\
\hline Positive & $0(0)$ & $4(17.4)$ & \\
\hline
\end{tabular}

In ER+ breast cancer, $\mathrm{PR}$ expression was the only clinicopathological characteristics that showed difference between $E R+/ A R$ - and $E R+/ A R+$ groups. The expression of $P R$ was significantly lower in $\mathrm{ER}+/ \mathrm{AR}$ - group than in $\mathrm{ER}+/ \mathrm{AR}+$ groups $(P=0.01)$, indicating a common mechanism behind the loss of expression for the two steroid hormone receptors (Table 1). In ER-breast cancer group, the expression of PR also showed the same trend though the $P$ value was marginal $(P=0.09)$. Patients diagnosed with ER-/AR+ breast cancer were 9 years older than those with ER-/AR- breast cancer, consistent with previous findings [3]. The histologic grade of ER-/AR+ and ER-/AR-groups showed a significant difference with AR loss correlated with a more advanced histologic grade. Nevertheless, the positivity of CK5/6 and EGFR which can be served as an indicator for basal-like character was not different between the ER-/AR+ and 
ER-/AR- group (Table 2). The above results indicated that AR-loss in ER- breast cancer has stronger impact than AR-loss in ER+ breast cancer. To further confirm this, Ki67 proliferation index was plotted and compared (Figure 2). No difference was detected in ER+ breast cancer while the Ki67 index was much higher in ER-/AR- group than in ER-/AR+ group.

\section{Estrogen receptor expression correlates with androgen receptor expression}

To further look at the correlation between ER and AR, the expression of them in IHC were plotted in Figure 3A. In IHC level, it can be noticed that though the expression of AR was mostly enriched in ER-high expression cases, there were many cases in which the expression of AR and ER were discordant. Also, we have selected 466 cases of breast cancer in TCGA by excluding the HER2-enriched cases. The expression of AR and ESR1 genes were displayed as heatmap in Figure 3B. The expression of AR and ESR1 were highly correlated. To further look at the correlation of AR and ER in different subtypes of breast cancer, the expression of AR and ESR1 in the five molecular subtype of breast cancer along with in normal breast tissue was plotted in Figure 4. Compared with normal breast tissue, expression of AR and ESR1 were higher in luminal A and B subtype and lower in basal-like subtype. Whereas, in HER2-enriched subtype, AR showed higher expression compared with normal breast tissue while ESR1 was expressed at a lower level than normal breast tissue. The correlation between the expression of AR and ESR1 was only significant in luminal A and basal-like subtype while not significant in luminal B and HER2-enriched subtype (Figure 5).

\section{Androgen receptor expression regulation was different in ER+ and ER-breast cancer}

To further look at the molecular features related with AR-expression in ER+ and ER- breast cancers, the above 466 breast cancer cases from TCGA were divided into AR-high and AR-low groups according to AR expression with the median expression value of AR as the threshold. Among all breast cancer cases, 406 of them were ER positive and 60 of them were ER negative. The baseline clinicopathological characteristics and comparison between AR-high and AR-low groups in ER+ and ER- breast cancers were listed in Supplementary Table 1 and Supplementary Table 2 respectively. Deferentially expressed genes between AR-high and AR-low groups were identified in ER+ and ER- breast cancer respectively. In ER+ breast cancer, the upregulated and downregulated genes between AR-high and AR-low groups were plotted in Figure 6A while those upregulated and downregulated in ER-breast cancer were plotted in Figure 6B. To analyze the similarity of the deferentially expressed genes (DEGs) between the ER+ and ERbreast cancer, the number of DEGs and the number of overlapped genes was plotted in Figure $6 \mathrm{C}$. The overlapped genes among the four DEG groups were designated as group I-IV respectively. The genelist for group I-IV were provided in Supplementary Table 3. Most of the DEGs have no overlap, suggesting molecular mechanisms related with AR loss were different between ER+ and ER-breast cancer.

\section{Methods}

\section{Patient selection}


The pathology database in Peking university Cancer hospital (PUCH) was queried and all breast core need biopsy (CNB) cases diagnosed from September 2019 to May 2020 were retrieved. A total of 323 breast carcinoma cases were selected. The cases were reviewed by two experienced pathologists ( $Y$ Liu and $\mathrm{M}$ Long). Ki-67 score is defined as the percentage of positively nuclear stained cells divided by the total number of malignant cells scored. When the staining is homogenous across sample, global Ki-67 score was used and for heterogenous staining $\mathrm{Ki}-67$ score counted in hot spots region. For breast cancer from TCGA, UCSC Xena an online exploration tool for public and private, multi-omic, and clinical/phenotype data, was used to download data of selected samples [18]. The 'TCGA Breast Cancer (BRCA)' cohort in the UCSC Xena was selected. All raw data used was downloaded from the 'Phenotypes TCGA Hub'.

\section{Analysis of differentially expressed genes}

The Fragments Per Kilobase of transcript per Million mapped reads upper quartile (FPKM-UQ) RNA-seq data were log2-transformed before further process. The FPKM-UQ is implemented at the GDC on genelevel read counts that are produced by HTSeq and based on a modified version of the FPKM normalization method [19]. The log2-transformed FPKM-UQ data were analyzed using limma20 (Version 3.44.3) functions ImFit, eBayes and topTable to identify DEGs [20]. Student t-test was utilized to calculate the $P$ values of genes. Genes with $P<0.05$ were considered as DEGs [21]. $P$ values were calculated as two-sided, with statistical significance declared for $P$ less than 0.05 .

\section{Discussion}

In this study, AR was expressed in $76 \%$ and $47 \%$ of ER+ and ER- breast cancer respectively in PUCH cohort. Our results showed that AR loss was associated with distinctive clinicopathological characteristics in ER+ and ER- breast cancer. While AR-expression only associates with PR positivity in ER+ breast cancer, it correlates with greater age at diagnosis and less advanced histologic grade. Our findings differ with previous study in which AR expression was found associated with lower histologic grade, pathological T stage in ER+ breast cancer but not in ER- breast cancer [22].

Molecular subtyping of TNBC identified that about $15-20 \%$ of TNBC can be classified as luminal androgen receptor (LAR) subtype which has greater age at diagnosis and low proliferation index [23-25]. However, for AR-positive TNBC, the report on the age at diagnosis compared with other TNBC is controversial [3, 26-30]. Moreover, previous study has identified no difference between ER-/AR+ and ER-/AR- breast cancer in terms of age at diagnosis [22]. Our result showed that ER-/AR+ breast cancer shares similar characteristics with LAR in terms of low proliferation index and older age of diagnosis. Also, we found that the expression of AR was correlated with different molecular features in ER+ and ERbreast cancer, suggesting that the role of AR in ER+ breast cancer may be distinct from those in ERbreast cancer.

There are several limitations of our study. First, the PUCH cohort was a retrospective study without survival information, thus the prognostic value of AR-loss in ER+ and ER-breast cancer cannot be 
investigated. Secondly, our analysis only focused on the HER2-negative breast cancer, previous studies demonstrated that the correlation between AR pathway activity and AR expression varied in HER2positive and HER2-negative breast cancer [14, 31].

\section{Conclusions}

Our findings demonstrate that the expression of $A R$ is associated with distinctive clinicopathological and molecular features in ER-positive and ER-negative breast cancer. Further characterization of the altered pathways and molecular features associated with AR expression in both ER+ and ER- breast cancer is required for the precise application of androgen receptor targeted therapy.

\section{Declarations}

All data used in this publication were generated by the TCGA project. The authors declare no competing interest.

\section{Acknowledgments}

The results here are in part based upon data generated by the TCGA Research Network: https://www.cancer.gov/tcga.

\section{Authors' contributions}

TH and ML contributed to the conception of the study; TH, SW, YL and ML performed the data analyses; YL and GZ contributed to the methodology; YL, GZ and SW helped the manuscript writing with constructive discussion; $\mathrm{TH}$ and $\mathrm{ML}$ wrote the final manuscript.

\section{Funding}

The author(s) disclosed receipt of the following financial support for the research, authorship, and/or publication of this article: This work was supported by the National Key Research and Development Program of China (Grant No. 2021YFE0203200), the National Natural Science Foundation of China (Grant No. 82002979, 92059105), the Beijing Municipal Natural Science Foundation (Grant No. 7202212), Scientific Research and Development Funds of Peking University People's Hospital (Grant No. RDY202016) and the Young Investigator Program of Peking University Health Science Center (Grant No. BMU2021PYB013, BMU2020PYB022).

\section{Ethics declarations}

\section{Ethics approval}

The study was approved by Peking University Cancer Hospital ethics committee (Reference number 2020KT113). 


\section{Consent for publication}

Written consent was obtained from all patients participated in this study.

\section{Competing interests}

None.

\section{Availability of data and materials}

The dataset supporting the conclusions of this article is included within the manuscript.

\section{References}

1. Knight WA 3rd, Osborne CK, Yochmowitz MG, McGuire WL. Steroid hormone receptors in the management of human breast cancer. Ann Clin Res. 1980;12(5):202-7.

2. Li Y, Yang D, Yin X, Zhang X, Huang J, Wu Y, Wang M, Yi Z, Li H, Li H, et al. Clinicopathological Characteristics and Breast Cancer-Specific Survival of Patients With Single Hormone ReceptorPositive Breast Cancer. JAMA Netw Open. 2020;3(1):e1918160.

3. Astvatsaturyan $\mathrm{K}$, Yue $\mathrm{Y}$, Walts AE, Bose S. Androgen receptor positive triple negative breast cancer: Clinicopathologic, prognostic, and predictive features. PLoS One. 2018;13(6):e0197827.

4. Niemeier LA, Dabbs DJ, Beriwal S, Striebel JM, Bhargava R. Androgen receptor in breast cancer: expression in estrogen receptor-positive tumors and in estrogen receptor-negative tumors with apocrine differentiation. Mod Pathol. 2010;23(2):205-12.

5. Rangel N, Rondon-Lagos M, Annaratone L, Osella-Abate S, Metovic J, Mano MP, Bertero L, Cassoni P, Sapino A, Castellano I. The role of the AR/ER ratio in ER-positive breast cancer patients. Endocr Relat Cancer. 2018;25(3):163-72.

6. Vera-Badillo FE, Templeton AJ, de Gouveia P, Diaz-Padilla I, Bedard PL, Al-Mubarak M, Seruga B, Tannock IF, Ocana A, Amir E. Androgen receptor expression and outcomes in early breast cancer: a systematic review and meta-analysis. J Natl Cancer Inst. 2014;106(1):djt319.

7. Bozovic-Spasojevic I, Zardavas D, Brohee S, Ameye L, Fumagalli D, Ades F, de Azambuja E, Bareche Y Piccart M, Paesmans M, et al. The Prognostic Role of Androgen Receptor in Patients with Early-Stage Breast Cancer: A Meta-analysis of Clinical and Gene Expression Data. Clin Cancer Res. 2017;23(11):2702-12.

8. Jiang HS, Kuang XY, Sun WL, Xu Y, Zheng YZ, Liu YR, Lang GT, Qiao F, Hu X, Shao ZM. Androgen receptor expression predicts different clinical outcomes for breast cancer patients stratified by hormone receptor status. Oncotarget. 2016;7(27):41285-93.

9. Kensler KH, Regan MM, Heng YJ, Baker GM, Pyle ME, Schnitt SJ, Hazra A, Kammler R, Thurlimann B, Colleoni $\mathrm{M}$, et al. Prognostic and predictive value of androgen receptor expression in 
postmenopausal women with estrogen receptor-positive breast cancer: results from the Breast International Group Trial 1-98. Breast Cancer Res. 2019;21(1):30.

10. Hickey TE, Robinson JL, Carroll JS, Tilley WD. Minireview: The androgen receptor in breast tissues: growth inhibitor, tumor suppressor, oncogene? Mol Endocrinol. 2012;26(8):1252-67.

11. D'Amato NC, Gordon MA, Babbs B, Spoelstra NS, Carson Butterfield KT, Torkko KC, Phan VT, Barton VN, Rogers TJ, Sartorius CA, et al. Cooperative Dynamics of AR and ER Activity in Breast Cancer. Mol Cancer Res. 2016;14(11):1054-67.

12. Hickey TE, Selth LA, Chia KM, Laven-Law G, Milioli HH, Roden D, Jindal S, Hui M, Finlay-Schultz J, Ebrahimie $\mathrm{E}$, et al. The androgen receptor is a tumor suppressor in estrogen receptor-positive breast cancer. Nat Med. 2021;27(2):310-20.

13. Doane AS, Danso M, Lal P, Donaton M, Zhang L, Hudis C, Gerald WL. An estrogen receptor-negative breast cancer subset characterized by a hormonally regulated transcriptional program and response to androgen. Oncogene. 2006;25(28):3994-4008.

14. Ni M, Chen Y, Lim E, Wimberly H, Bailey ST, Imai Y, Rimm DL, Liu XS, Brown M. Targeting androgen receptor in estrogen receptor-negative breast cancer. Cancer Cell. 2011;20(1):119-31.

15. Traina TA, Miller K, Yardley DA, Eakle J, Schwartzberg LS, O'Shaughnessy J, Gradishar W, Schmid P, Winer E, Kelly C, et al. Enzalutamide for the Treatment of Androgen Receptor-Expressing TripleNegative Breast Cancer. J Clin Oncol. 2018;36(9):884-90.

16. Krop I, Abramson V, Colleoni M, Traina T, Holmes F, Garcia-Estevez L, Hart L, Awada A, Zamagni C, Morris PG, et al. A Randomized Placebo Controlled Phase II Trial Evaluating Exemestane with or without Enzalutamide in Patients with Hormone Receptor-Positive Breast Cancer. Clin Cancer Res. 2020;26(23):6149-57.

17. Narayanan R, Coss CC, Dalton JT. Development of selective androgen receptor modulators (SARMs). Mol Cell Endocrinol. 2018;465:134-42.

18. Goldman MJ, Craft B, Hastie M, Repecka K, McDade F, Kamath A, Banerjee A, Luo Y, Rogers D, Brooks AN, et al. Visualizing and interpreting cancer genomics data via the Xena platform. Nat Biotechnol. 2020;38(6):675-8.

19. Jensen MA, Ferretti V, Grossman RL, Staudt LM. The NCI Genomic Data Commons as an engine for precision medicine. Blood. 2017;130(4):453-9.

20. Ritchie ME, Phipson B, Wu D, Hu Y, Law CW, Shi W, Smyth GK. limma powers differential expression analyses for RNA-sequencing and microarray studies. Nucleic Acids Res. 2015;43(7):e47.

21. Bland JM, Altman DG. The logrank test. BMJ. 2004;328(7447):1073.

22. Tsang JY, Ni YB, Chan SK, Shao MM, Law BK, Tan PH, Tse GM. Androgen receptor expression shows distinctive significance in ER positive and negative breast cancers. Ann Surg Oncol. 2014;21(7):2218-28.

23. Yin L, Duan JJ, Bian XW, Yu SC. Triple-negative breast cancer molecular subtyping and treatment progress. Breast Cancer Res. 2020;22(1):61. 
24. Masuda H, Baggerly KA, Wang Y, Zhang Y, Gonzalez-Angulo AM, Meric-Bernstam F, Valero V, Lehmann BD, Pietenpol JA, Hortobagyi GN, et al. Differential response to neoadjuvant chemotherapy among 7 triple-negative breast cancer molecular subtypes. Clin Cancer Res. 2013;19(19):5533-40.

25. Jiang YZ, Ma D, Suo C, Shi J, Xue M, Hu X, Xiao Y, Yu KD, Liu YR, Yu Y, et al. Genomic and Transcriptomic Landscape of Triple-Negative Breast Cancers: Subtypes and Treatment Strategies. Cancer Cell. 2019;35(3):428-40 e425.

26. Angajala A, Mothershed E, Davis MB, Tripathi S, He Q, Bedi D, Dean-Colomb W, Yates C. Quadruple Negative Breast Cancers (QNBC) Demonstrate Subtype Consistency among Primary and Recurrent or Metastatic Breast Cancer. Transl Oncol. 2019;12(3):493-501.

27. Kim EY, Lee KH, Yun JS, Park YL, Park CH, Do SI, Chae SW. Clinicopathologic significance of androgen receptor expression and discordant receptor status during progression in breast cancer. Int J Clin Exp Pathol. 2017;10(7):7929-39.

28. Dieci MV, Tsvetkova V, Griguolo G, Miglietta F, Mantiero M, Tasca G, Cumerlato E, Giorgi CA, Giarratano T, Faggioni G, et al. Androgen Receptor Expression and Association With Distant DiseaseFree Survival in Triple Negative Breast Cancer: Analysis of 263 Patients Treated With Standard Therapy for Stage I-III Disease. Front Oncol. 2019;9:452.

29. Sunar V, Sarici HTD, Ates F, Akin O, Baspinar S, Aksoy B, Altundag S. K: Association between androgen receptor status and prognosis in triple negative breast cancer. J BUON. 2018;23(5):132530 .

30. Pistelli M, Caramanti M, Biscotti T, Santinelli A, Pagliacci A, De Lisa M, Ballatore Z, Ridolfi F, Maccaroni E, Bracci R, et al. Androgen receptor expression in early triple-negative breast cancer: clinical significance and prognostic associations. Cancers (Basel). 2014;6(3):1351-62.

31. Liu D. AR pathway activity correlates with AR expression in a HER2-dependent manner and serves as a better prognostic factor in breast cancer. Cell Oncol (Dordr). 2020;43(2):321-33.

\section{Figures}




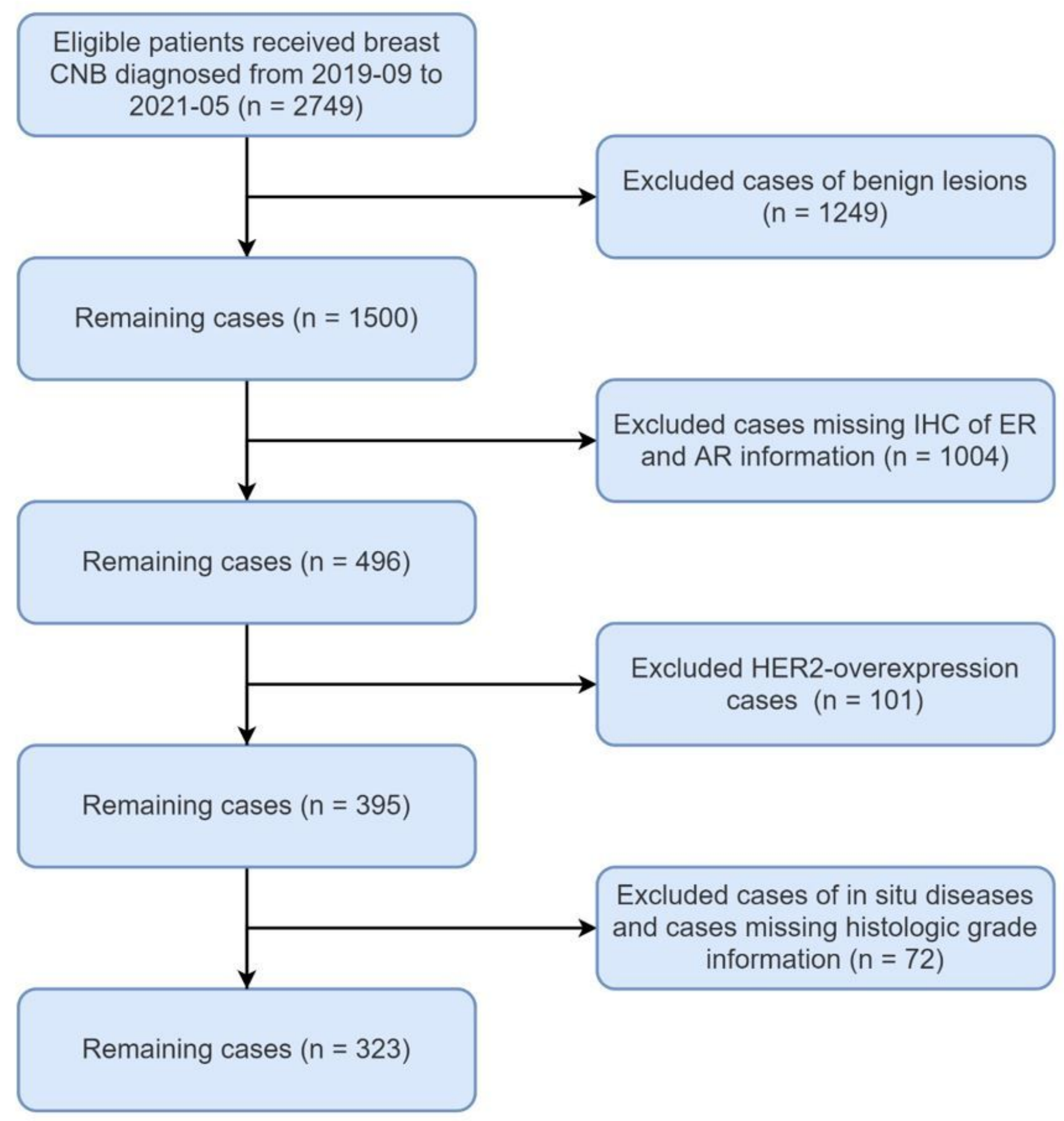

Figure 1

Flow chart of patient selection form the Peking University Cancer Hospital (PUCH) cohort 

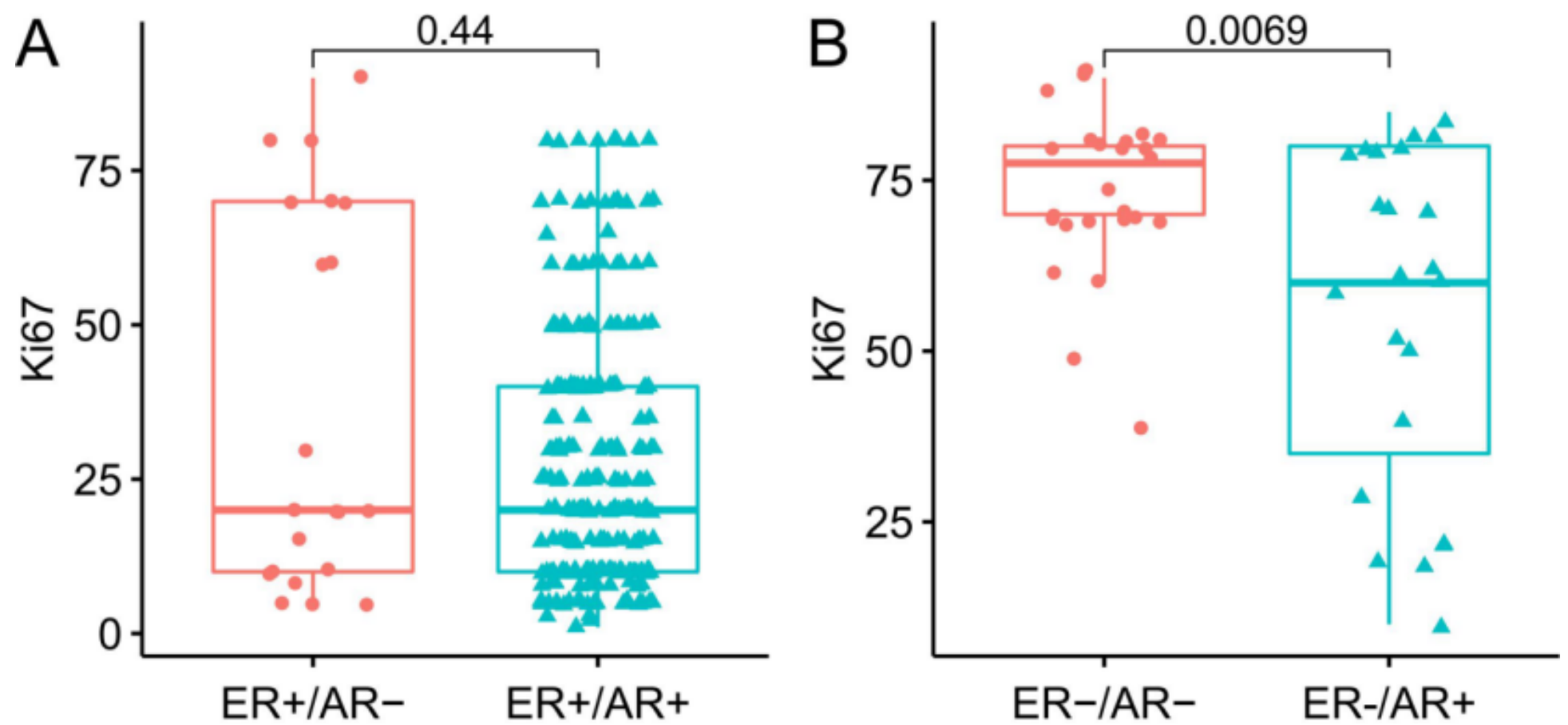

Figure 2

Comparison of Ki67 expression between AR+ and AR-groups. Box plot of Ki67 proliferation index in ER+ breast cancer (A) and in ER- breast cancer (B) respectively in the PUCH cohort.

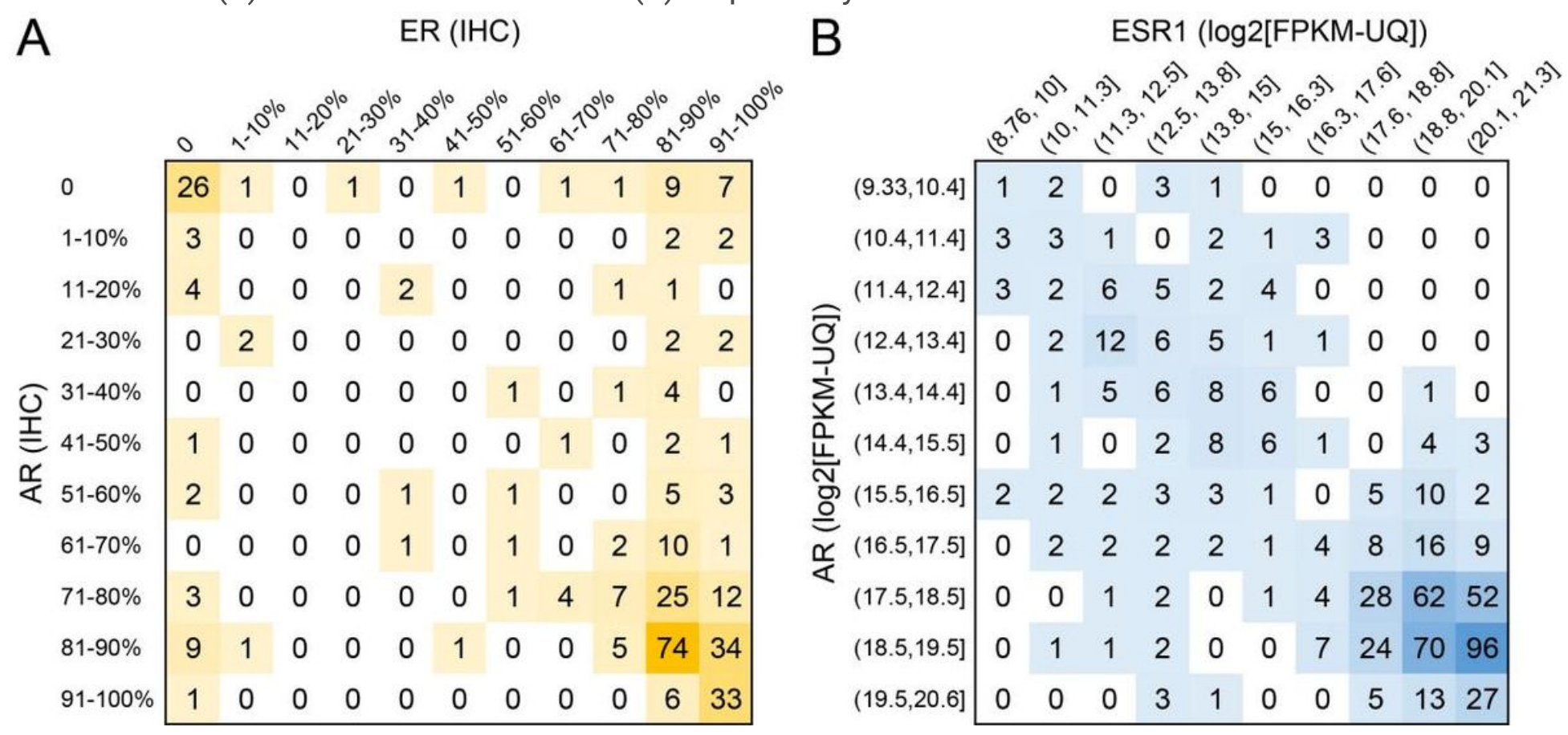

\section{Figure 3}

Summarize of number of patients with specific AR and ER expression (A) Cell percentage categories of $A R$ and ER expression in IHC. Case number of each specific AR and ER expression status were summarized and presented. AR and ER expression were reported either as negative or as the percentage of cell showed positive expression which were sub-grouped into 10 categories with a 10 percent interval. 
(B) The expression profile of AR and ESR1 in HER2- breast cancers from TCGA. The expression of AR and ESR1 gene were divided into ten equal parts according to the maximum and minimum value and presented in heatmap.

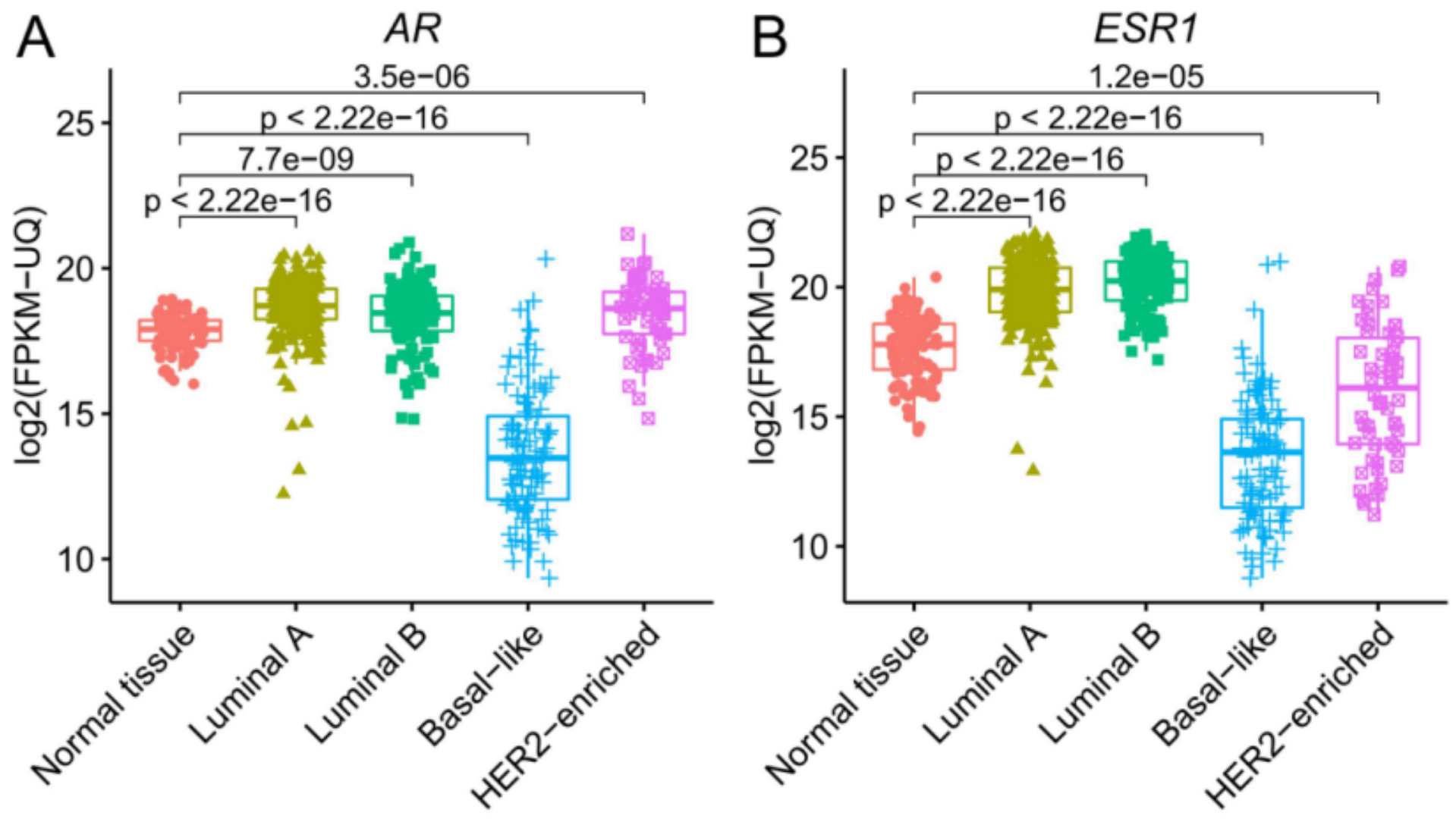

Figure 4

Expression of AR and ESR1 gene in normal breast tissue and four intrinsic subtypes of breast cancer in TCGA cohort. 


\section{Luminal A}

$$
R=0.44, p=1.1 \mathrm{e}-12
$$

$R=0.14, p=0.11$

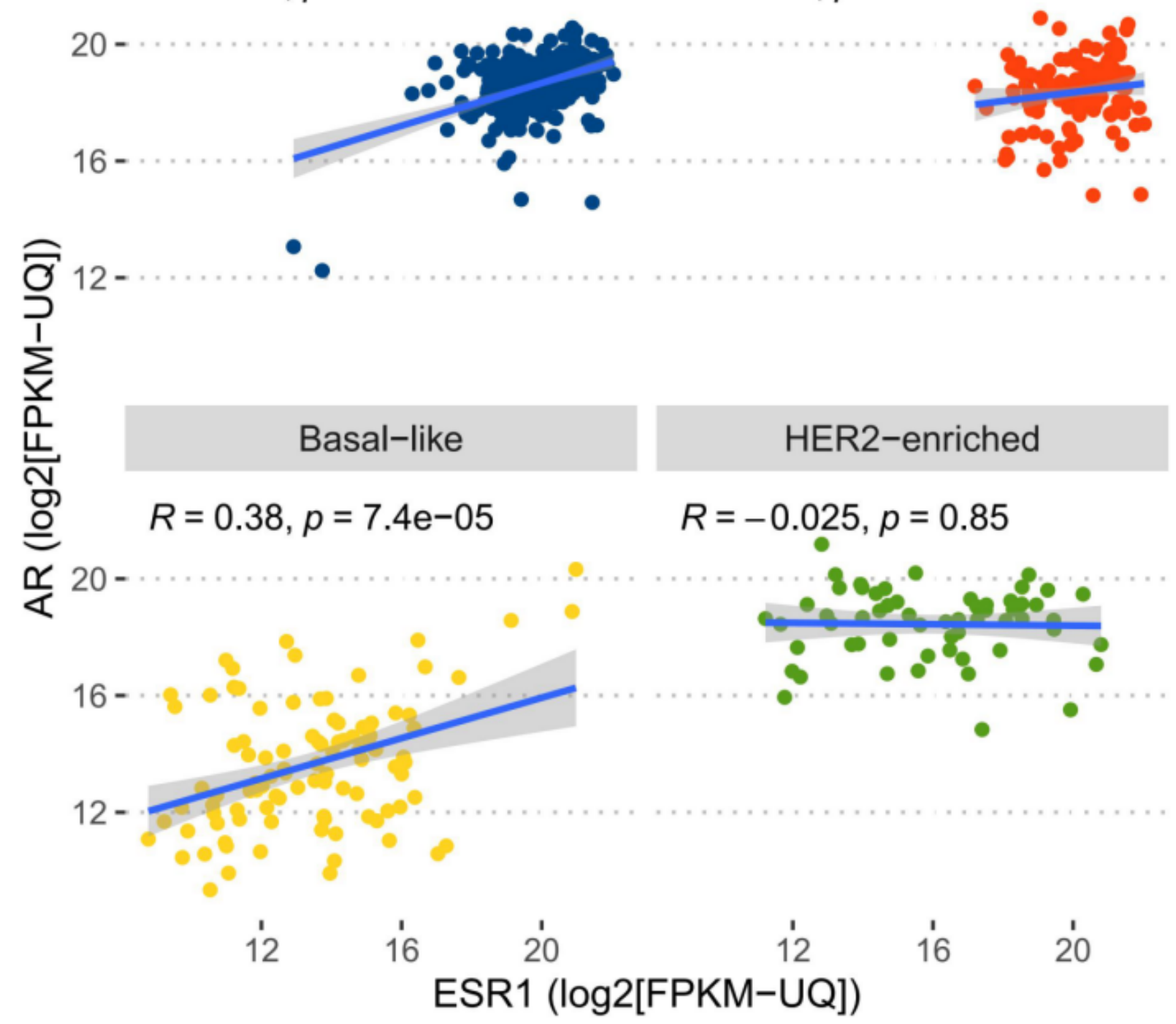

Figure 5

Correlation between the expression of AR and ESR1 in four intrinsic subtypes of breast cancer in TCGA cohort. Correlation plot of the expression of AR and ESR1 in four intrinsic subtypes of breast cancer. Regression line, Pearson's correlation coefficient and $p$-value were also displayed. 

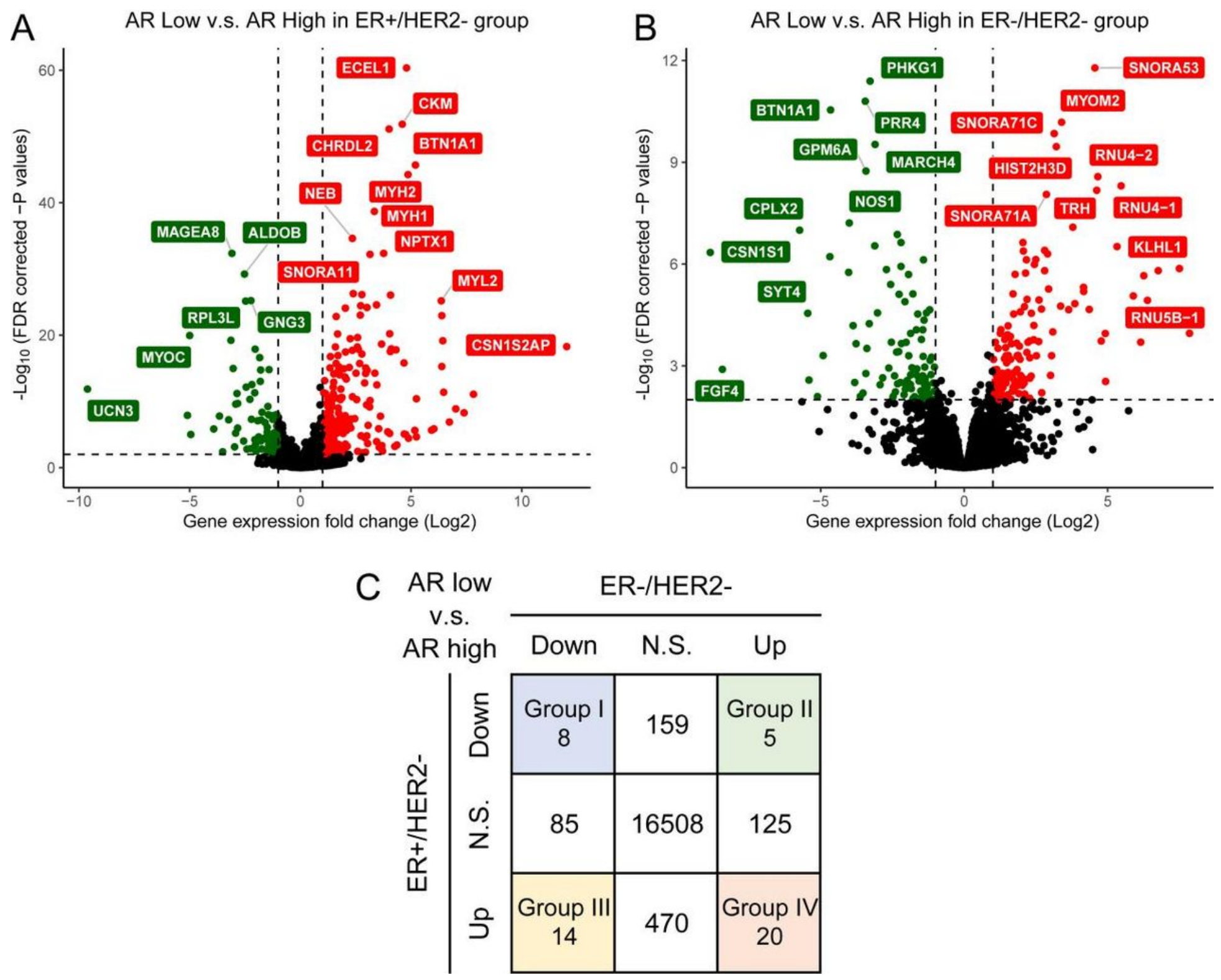

Figure 6

Molecular features associated with AR expression in ER+ and ER- breast cancer are distinct. (A-B) Differentially expressed genes (Volcano plot) of AR low expression and AR high expression groups in ER+ and ER- breast cancer from TCGA (Red: upregulated; Blue: downregulated; Black: no significant change).

(C) Groups of DEGs identified above. All the genes are classified according to whether it was differentially expressed between AR low and AR high groups in ER+ and ER- breast cancer. A total of 9 groups genes can be identified including four groups (group I-IV) composed of overlapped gene.

\section{Supplementary Files}

This is a list of supplementary files associated with this preprint. Click to download.

- SupplementaryTable1.docx 
- SupplementaryTable2.docx

- SupplementaryTable3.xls 